\title{
Độ bền lâu của bê tông sử dụng xỉ hạt lò cao nghiền mịn làm phụ gia khoáng
}

\author{
Phan Văn Quỳnh ${ }^{1 *}$, Lê Việt Hùng ${ }^{1}$, Phạm Hữu Thiên ${ }^{1}$ \\ ${ }^{1}$ Viện Vật liệu xây dựng, Số 235 Nguyễn Trãi, Q. Thanh Xuân, Hà Nội
}

\section{TỪ KHOÁ}

Bê tông xỉ hạt lò cao nghiền mịn Xỉ hạt lò cao nghiền mịn

Xỉ

Độ bền lâu

Phụ gia khoáng

\section{KEYWORDS}

Ground-granulated blast-furnace slag concrete

Slag

Durability

Mineral admixture

\section{TÓM TẮT}

Xỉ lò cao (GBFS) là sản phẩm phụ của quá trình luyện gang trong lò cao. Ở Việt Nam hiện nay, xỉ lò cao chủ yếu được nghiền cùng clanke để sản xuất xi măng pooc lăng hỗn hợp. Việc sử dụng xỉ hạt lò cao nghiền mịn (GGBFS) làm phụ gia khoáng cho bê tông còn là vấn đề mới. Bài báo này trình bày ảnh hưởng của xỉ lò cao nghiền mịn khi sử dụng làm phụ gia khoáng đến một số tính chất liên quan đến độ bền lâu của bê tông như khả năng chống thấm nước, chống thấm ion clo, độ bền sun phát, độ co khô và phản ứng kiềm cốt liệu. Bê tông sử dụng GGBFS làm phụ gia khoáng với tỷ lệ GGBFS 20-70\% và xi măng nền là PC40. Kết quả nghiên cứu cho thấy sử dụng xỉ lò cao nghiền mịn thay thế một phần xi măng có thể cải thiện mức độ chống thấm ion clo, chống thấm nước và khả năng ngăn cản phản ứng kiềm cốt liệu của bê tông. Ngoài ra, sử dụng GGBFS còn giúp cải thiện độ bền sun phát của thanh vữa ngâm trong môi trường sun phát $\left(\mathrm{Na}_{2} \mathrm{SO}_{4}\right)$.

\section{ABSTRACT}

Granulated blast-furnace slag (GBFS) is a by-product of iron and steel-making from a blast furnace. In Vietnam today, granulated blast furnace slag is mainly ground with clinker to produce portland blended cement. The use of ground-granulated blast furnace slag (GGBFS) as a mineral admixture for concrete is still a new issue. This paper presents the effect of ground-granulated blast furnace slag, which was used as a mineral admixture on some properties related to the durability of concrete such as waterproofing, chloride ion impermeability, sulfate resistance and aggregate alkali reactivity. Concrete use GGBFS as a mineral admixture with the ratio of GGBFS 20 - 70\% with the control-cement PC40. Research results show that using GGBFS to partially replace cement can improve chloride ion impermeability resistance, waterproofing and ability to prevent the aggregate alkaline reaction of concrete. In addition, using GGBFS also improves the sulfate resistance of mortar specimens, which were immersed in a sulfate solution $\left(\mathrm{Na}_{2} \mathrm{SO}_{4}\right)$.

\section{Giới thiệu}

Mặc dù bê tông được sử dụng rất phổ biến trong xây dựng hàng trăm năm qua nhưng nó vẫn có những yếu điểm như dòn, dễ bị nứt, suy giảm độ bền trong các điều kiện môi trường biển, hóa chất, thay đổi nhiệt độ, độ ẩm... Đồng thời, bê tông truyền thống được cho là chưa có tính bền vững vì sử dụng nhiều xi măng dẫn đến làm tăng lượng phát thải khí nhà kính trên trái đất do sản xuất xi măng gây ra. Vì vậy, từ giữa thế kỷ $X X$ việc nghiên cứu và sử dụng các loại phụ gia bao gồm cả phụ gia hóa học và phụ gia khoáng cho xi măng và bê tông đã được tiến hành rộng rãi ở nhiều nước trên thế giới nhằm nâng cao chất lượng, đồng thời khắc phục các nhược điểm của bê tông. Các loại phụ gia khoáng có nguồn gốc từ chất thải của các ngành công nghiệp nặng bao gồm silica fume, tro bay nhiệt điện, xỉ lò cao nghiền mịn và chất thải nông nghiệp như tro trấu được xem là các loại phụ gia khoáng "xanh" và "bền vững" bởi vì chúng vừa có tác dụng cải thiện tính năng của bê tông giúp gián tiếp giảm lượng phát thải khí nhà kính phát sinh từ ngành công nghiệp sản xuất xi măng. Bê tông hiện đại có thành phần không chỉ cốt liệu, xi măng và nước mà thường bao gồm thêm thành phần nguyên liệu thứ tư là phụ gia (hóa và khoáng) [1].

Trên thế giới, sự phát triển công nghiệp và năng lượng ngày càng tăng dẫn tới phát sinh khối lượng lớn các loại phế thải công nghiệp, đặc biệt là phế thải ngành công nghiệp luyện gang, thép và nhiệt điện sử dụng nhiên liệu hóa thạch. Căn cứ theo số liệu công bố về sản lượng sản xuất gang thép trên thế giới năm 2017 của Hiệp hội thép thế giới, tổng sản lượng gang lò cao sản xuất ra trong năm 2016 và 2017 khoảng 1163 triệu tấn/năm, lượng xỉ hạt lò cao phát sinh ước tính khoảng $30 \%$ sản lượng gang, tức khoảng 350 triệu tấn/năm. Đây là lượng chất thải khổng lồ, nhưng cũng đồng thời là nguồn nguyên liệu dồi dào để sử dụng làm nguyên vật liệu thay thế tài nguyên thiên nhiên.

Tại Việt Nam, vấn đề nghiên cứu sử dụng xỉ hạt lò cao (GBFS) cho sản xuất xi măng, bê tông được quan tâm, nghiên cứu từ khoảng những năm 1970. Tuy nhiên, số lượng và phạm vi các nghiên cứu còn hạn chế, chỉ dừng lại ở mức thử nghiệm một số tỷ lệ pha trộn xỉ vào xi măng để đánh giá các tính chất thông thường của xi măng. Chưa có công trình nghiên cứu nào thực hiện đầy đủ, có hệ thống về đặc tính kỹ thuật của xi măng xỉ, đặc biệt là bê tông sử dụng xi măng xỉ hoặc 
GGBFS làm phụ gia khoáng. Trong những năm trước đây, xỉ hạt lò cao của các nhà máy luyện gang chủ yếu được bán ở dạng nguyên khai cho các nhà máy xi măng để nghiền cùng với clanhke xi măng tạo thành xi măng poóc hỗn hợp tại nhà máy. Do đặc tính của xỉ hạt lò cao là khó nghiền hơn khá nhiều so với clanhke xi măng, nên khi nghiền chung với clanhke trong máy nghiền bi thì độ mịn của xỉ ở mức thấp hơn so với xi măng [2]. Điều này làm hạn chế các ưu điểm của GGBFS, đồng thời làm giảm nhiều cường độ tuổi sớm cũng như dễ gây hiện tượng tách nước của hỗn hợp bê tông. Hiện nay ở nước ta, sản phẩm GGBFS đã bắt đầu được sản xuất ở quy mô công nghiệp và đã được đưa ra sử dụng tại một số công trình xây dựng. Hiện tại có hai nhà máy nghiền GBFS quy mô lớn là nhà máy của Công ty Thép Hòa Phát tại Hải Dương và Quảng Ngãi và nhà máy nghiền GBFS của Công ty Tài nguyên CHC Việt Nam tại Bà Rịa-Vũng Tàu. Tổng công suất của 3 nhà máy theo thiết kế là 2,5 triệu tấn GGBFS/năm. Hiện nay số công trình xây dựng, nhà sản xuất bê tông sử dụng GGBFS vẫn còn ít. Công ty Hòa Phát mới chủ yếu cấp cho các dự án xây dựng do tập đoàn này xây dựng; sản phẩm của Công ty Công ty Tài nguyên CHC Việt Nam cũng mới chủ yếu cung cấp cho dự án xây dựng đầu tư nước ngoài, các nhà sản xuất bê tông, xi măng có vốn nước ngoài.

Bài báo này trình bày ảnh hưởng của xỉ lò cao nghiền mịn khi sử dụng làm phụ gia khoáng đến một số tính chất liên quan đến độ bền lâu của bê tông như cường độ nén, khả năng chống thấm nước, chống thấm ion clo, độ bền sun phát, và phản ứng kiềm cốt liệu. Bê tông sử dụng GGBFS làm phụ gia khoáng với tỷ lệ GGBFS 20 đến 70 \% với xi măng nền là PC40. Kết quả nghiên cứu cho thấy sử dụng xỉ lò cao nghiền mịn thay thế một phần xi măng có thể cải thiện mức độ chống thấm ion clo, chống thấm nước và khả năng ngăn cản phản ứng kiềm cốt liệu của bê tông. Ngoài ra, sử dụng GGBFS còn giúp cải thiện độ bền sun phát của thanh vữa ngâm trong môi trường natri sun phát.

\section{Vật liệu và phương pháp nghiên cứu \\ 2.1. Vật liệu nghiên cứu}

Xi măng: xi măng poóc lăng PC40 Nghi Sơn có các tính chất kỹ thuật đạt yêu cầu theo TCVN 2682:2009.

Cốt liệu nhỏ: là cát sông, từ nguồn cát sông Lô, Việt Trì, Phú Thọ, có mô đun độ lớn 2,6. Các chỉ tiêu kỹ thuật của mẫu cát phù hợp loại cát thô theo TCVN 7570:2006.

Cốt liệu lớn: là đá dăm từ đá vôi cỡ hạt 5 đến $20 \mathrm{~mm}$ từ mỏ đá khu vực Phủ Lý, Hà Nam. Các chỉ tiêu kỹ thuật của mẫu đá phù hợp cốt liệu lớn loại 5 đến 20 mm theo TCVN 7570:2006.

Phụ gia siêu dẻo: loại phụ gia siêu dẻo phổ biến trên thị trường gốc Polycarboxylate (PCE). Loại lựa chọn sử dụng cho nghiên cứu là phụ gia MasterGlenium ${ }^{\circledR}$ SKY 8735 của hãng BAFS. Đây là loại phụ gia gốc polycarboxylate, có độ giảm nước 15 đến $20 \%$, phù hợp với loại G theo TCVN 8826:2011.

Xỉ hạt có cao nghiền mịn sử dụng trong đề tài được lấy từ nhà máy thép Formosa Hà Tĩnh, có tỷ diện $>4000 \mathrm{~cm}^{2} / \mathrm{g}$. Thành phần khoáng của xỉ hạt lò cao nghiền mịn Formosa chủ yếu là pha vô định hình ( 98 \%). Các chỉ tiêu cơ lý và thành phần hóa của xỉ hạt lò cao được trình bày trong Bảng 1 .

Bảng 1. Thành phần hóa xỉ lò cao sử dụng cho nghiên cứu.

\begin{tabular}{|c|c|c|c|c|c|c|c|c|c|c|c|c|}
\hline MKN & $\mathrm{SiO}_{2}$ & $\mathrm{CaO}$ & $\mathrm{Al}_{2} \mathrm{O}_{3}$ & $\mathrm{Fe}_{2} \mathrm{O}_{3}$ & $\mathrm{MgO}$ & $\mathrm{SO}_{3}$ & $\mathrm{~K}_{2} \mathrm{O}$ & $\mathrm{Na}_{2} \mathrm{O}$ & $\mathrm{TiO}_{2}$ & $\mathrm{Cl}^{-}$ & $\mathrm{S}_{2}^{-}$ & Hệ số K \\
\hline 0,07 & 34,49 & 40,07 & 14,10 & 0,23 & 7,51 & 0,20 & 0,24 & 0,82 & 0,12 & $<0,001$ & 0,63 & 1,88 \\
\hline
\end{tabular}

\subsection{Phương pháp nghiên cứu}

Công tác thử nghiệm và xác định các tính chất của vật liệu và bê tông được sử dụng chủ yếu theo các phương pháp tiêu chuẩn trong hệ thống TCVN. Độ thấm nước, thấm ion clo, phản ứng kiềm - cốt liệu, độ bền sun phát được xác định theo các tiêu chuẩn TCVN 3116:1993, TCVN 9337:2012, TCVN 7572-14:2006, TCVN 7713:2007 tương ứng.

\section{Kết quả nghiên cứu và bàn luận}

Độ bền lâu của bê tông được định nghĩa là khả năng chống lại sự thâm nhập của các tác nhân xâm thực từ bên ngoài môi trường cũng như các tác nhân từ bên trong bản thân bê tông mà vẫn đảm bảo được các tính chất kỹ thuật yêu cầu. Trong nghiên cứu này đã khảo sát ảnh hưởng của GGBFS đến các chỉ tiêu độ chống thấm nước, độ chống thấm ion clo, độ bền sun phát và phản ứng kiềm - cốt liệu của bê tông.

\subsection{Khả năng chống thấm}

Khả năng chống thấm của bê tông được đánh giá thông qua mức độ thâm nhập ion clo bằng phương pháp đo điện lượng theo tiêu chuẩn ASTM C1202 (TCVN 9337:2012) và độ thấm nước theo tiêu chuẩn TCVN 3116:1993. Cấp phối bê tông được cho trên Bảng 2, với hàm lượng GGBFS thay thế xi măng từ 0 đến 50 \%, sử dụng xi măng PC40 Nghi Sơn. Bê tông có độ sụt $(16 \div 18) \mathrm{cm}$. Kết quả thí nghiệm thể hiện trong Bảng 3 và Hình 1 cho thấy, khả năng chống thấm nước cũng như khả năng chống thấm ion clo được cải thiện đáng kể khi sử dụng GGBFS thay thế xi măng. Mức độ cải thiện khả năng chống thấm tăng lên khi tăng hàm lượng GGBFS. Khi sử dụng đến 50 \% GGBFS thay thế xi măng, điện lượng truyền qua mẫu theo ASTM C1202 giảm từ 1527 (Culong) của mẫu đối chứng xuống còn 528 (Culong) và độ chống thấm nước tăng từ B12 lên đến B16.

Khả năng cải thiện tính chống thấm ion clo của bê tông khi sử dụng GGBFS theo các kết quả thí nghiệm đã chỉ ra cũng phù hợp với các kết quả của nhiều nghiên cứu được tổng hợp trong ACI 233 [3]. Theo đó, sự có mặt của xỉ làm cải thiện khả năng chống thấm của bê tông do phản ứng thủy hóa làm giảm bớt hàm lượng $\mathrm{Ca}(\mathrm{OH})_{2}$ trong hệ thống lỗ 
rỗng của đá xi măng, đồng thời tạo sản phẩm CSH làm giảm kích thước các lỗ rỗng trong đá xi măng và cải thiện vùng tiếp xúc giữa đá xi măng và cốt liệu, do đó làm tăng tính chống thấm của bê tông. Tác dụng nâng cao tính chống thấm của bê tông khi có mặt của xỉ cũng là nguyên nhân làm tăng khả năng chống ăn mòn cốt thép và khả năng bền trong môi trường sulfate của bê tông chứa xỉ.

Bảng 2. Các cấp phối bê tông sử dụng xi măng PC40.

\begin{tabular}{|c|c|c|c|c|c|c|c|c|c|}
\hline \multirow[b]{2}{*}{ STT } & \multirow[b]{2}{*}{ Ký hiệu mẫu } & \multirow{2}{*}{$\begin{array}{c}\text { Tỷ lệ GGBFS } \\
\text { (\%) }\end{array}$} & \multicolumn{6}{|c|}{ Thành phần cấp phối một $\mathrm{m}^{3}$ bê tông theo thiết kế } & \multirow{2}{*}{$\begin{array}{c}\text { Độ sụt } \\
\text { yêu cầu } \\
\text { (cm) }\end{array}$} \\
\hline & & & $\begin{array}{c}\text { Xi măng } \\
(\mathrm{kg})\end{array}$ & $\begin{array}{c}\text { GGBFS } \\
(\mathrm{kg})\end{array}$ & $\begin{array}{c}\text { Cát sông } \\
(\mathrm{kg})\end{array}$ & $\begin{array}{c}\text { Đá dăm } \\
\text { (kg) }\end{array}$ & PGHH (lít) & Nước (lít) & \\
\hline 1 & PC40S0 & 0 & 360 & 0 & 789 & 1079 & 3,60 & 170 & $16-18$ \\
\hline 2 & PC40S20 & 20 & 288 & 72 & 784 & 1079 & 3,60 & 170 & $16-18$ \\
\hline 3 & PC40S30 & 30 & 252 & 108 & 784 & 1079 & 3,60 & 170 & $16-18$ \\
\hline 4 & PC40S40 & 40 & 216 & 144 & 784 & 1079 & 3,60 & 170 & $16-18$ \\
\hline 5 & PC40S50 & 50 & 180 & 180 & 784 & 1079 & 3,60 & 170 & $16-18$ \\
\hline
\end{tabular}

Bảng 3. Độ thấm ion clo theo phương pháp đo điện lượng của bê tông với tỷ lệ sử dụng GGBFS và tỷ lệ N/CKD khác nhau.

\begin{tabular}{|c|c|c|c|c|c|c|}
\hline STT & Ký hiệu mẫu & $\begin{array}{c}\text { Hàm lượng } \\
\text { GGBFS (\%) }\end{array}$ & $\begin{array}{c}\text { Hàm lượng } \\
\text { CKD (kg) }\end{array}$ & $\begin{array}{c}\text { Điện lượng truyền qua } \\
\text { (cu lông) }\end{array}$ & $\begin{array}{c}\text { Đánh giá theo } \\
\text { ASTM C1202 }\end{array}$ & Độ thấm nước (cấp B) \\
\hline 1 & PC40 & 0 & 360 & 1527 & thấp & rất thấp \\
\hline 2 & PC40S20 & 20 & 360 & 935 & rất thấp & 12 \\
\hline 3 & PC40S30 & 30 & 360 & 631 & rất thấp & 16 \\
\hline 4 & PC40S40 & 40 & 360 & 539 & rất thấp & 16 \\
\hline 5 & PC40S50 & 50 & 360 & 528 & 16 \\
\hline
\end{tabular}

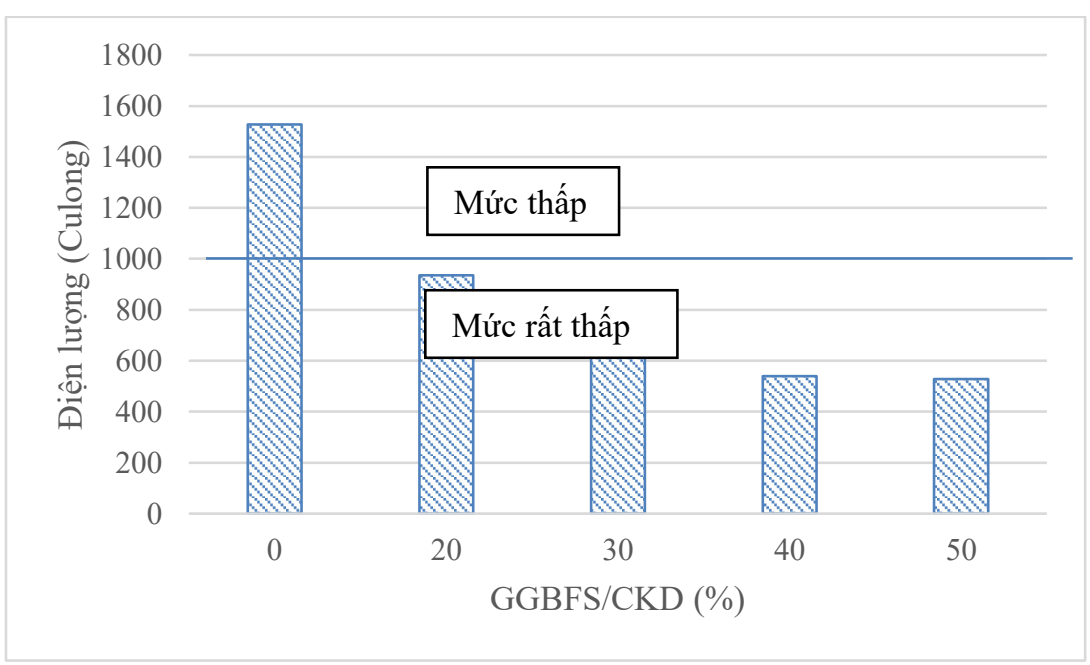

Hình 1. Độ thấm ion clo của bê tông sử dụng GGBFS.

\section{2. Độ bền sun phát}

Trong nghiên cứu này, khả năng bền trong môi trường sun phát của bê tông sử dụng chất kết dính chứa GGBFS và so sánh với mẫu xi măng PC40 được đánh giá trên mẫu thanh vữa thử nghiệm theo
TCVN 7713:2007 và được đánh giá so sánh với qui định kỹ thuật của xi măng poóc lăng phát hỗn hợp bền sun phát phù hợp theo TCVN 7711:2013. CKD chứa là xi măng hỗn hợp PC40-GGBFS, với tỷ lệ GGBFS là $20,30,40,50,60$ và $70 \%$ theo khối lượng CKD. Ngoài ra, theo nhiều kết quả nghiên cứu trước đây [2] thì khả năng bền sun 
phát của CKD chứa GGBFS còn phụ thuộc vào hàm lượng thạch cao (quy về $\mathrm{SO}_{3}$ ) trong $\mathrm{CKD}$. Đề tài này khảo sát ảnh hưởng của loại và tỷ lệ GGBFS với hàm lượng thạch cao (qui về $\mathrm{SO}_{3}$ ) trong $\mathrm{CKD} 2,5 \%$. Các mẫu được ngâm trong dung dịch $\mathrm{Na}_{2} \mathrm{SO}_{4} 5 \%$. Chi tiết cấp phối vật liệu đúc thành vữa cho thử nghiệm thể hiện trong Bảng 4 .

Từ kết quả thí nghiệm cho thấy, độ nở của thanh vữa tăng lên theo thời gian ngâm mẫu với tất cả các mẫu thử nghiệm. Khi tăng làm hượng GGBFS thay thế xi măng, độ nở sun phát của mẫu thử giảm xuống rõ rệt. Cụ thể ở tuổi 6 tháng, độ nở sun phát của mẫu đối chứng là $0,92 \%$ còn các mẫu sử dụng từ 30 đến $70 \%$ GGFFS có độ nở sun phát lần lượt là $0,197 \% ; 0,084 \% ; 0,109 \% ; 0,058 \%$ và $0,024 \%$ tương ứng với hàm lượng GGBFS là $30 \% ; 40 \% ; 50 \% ; 60 \%$ và $70 \%$.

Bảng 4. Cấp phối vật liệu đúc thanh vữa đo độ nở ngâm trong dung dịch $\mathrm{Na}_{2} \mathrm{SO}_{4} 5$ \%.

\begin{tabular}{|c|c|c|c|c|c|}
\hline TT & Ký hiệu mẫu & Tỷ lệ GGBFS (\%) & $\begin{array}{c}\text { Hàm lượng } \\
\text { SO3 (\%) }\end{array}$ & Tỷ lệ cát/CKD & Tỷ lệ N/CKD \\
\hline 1 & PC40 & 0 & 2,4 & 2,75 & 0,485 \\
\hline 2 & PC40S30 & 30 & 2,5 & 2,75 & 0,502 \\
\hline 3 & PC40S40 & 40 & 2,5 & 2,75 & 0,505 \\
\hline 4 & PC40S50 & 50 & 2,5 & 2,75 & 0,511 \\
\hline 5 & PC40S60 & 60 & 2,5 & 2,75 & 0,524 \\
\hline 6 & PC40S70 & 70 & 2,5 & 2,75 & 0,531 \\
\hline
\end{tabular}

Bảng 5. Kết quả độ nở sun phát của thanh vữa ngâm trong dung dịch $\mathrm{Na}_{2} \mathrm{SO}_{4} 5 \%$.

\begin{tabular}{|c|c|c|c|c|c|c|c|c|}
\hline \multirow{2}{*}{ STT } & Mã hóa cấp & \multicolumn{8}{|c|}{ Độ nở thanh vữa ngâm trong dung dịch Na2SO4 (\%) } \\
\cline { 3 - 10 } & phối & 1 tuần & 2 tuần & 1 tháng & 2 tháng & 3 tháng & $\mathbf{6}$ tháng & 9 tháng \\
\hline 1 & PC40 & $-0,049$ & 0,005 & 0,011 & 0,072 & 0,293 & 0,920 & $2,052^{*}$ \\
\hline 2 & PC40S30 & 0,011 & 0,034 & 0,038 & 0,051 & 0,082 & 0,197 & 0,482 \\
\hline 3 & PC40S40 & 0,005 & 0,042 & 0,044 & 0,041 & 0,059 & 0,084 & 0,213 \\
\hline 4 & PC40S50 & 0,015 & 0,041 & 0,044 & 0,040 & 0,057 & 0,109 & $0,154 *$ \\
\hline 5 & PC40S60 & 0,008 & 0,020 & 0,027 & 0,037 & 0,051 & 0,058 & 0,069 \\
\hline 6 & PC40S70 & 0,009 & 0,013 & 0,018 & 0,026 & 0,028 & 0,024 & 0,027 \\
\hline
\end{tabular}

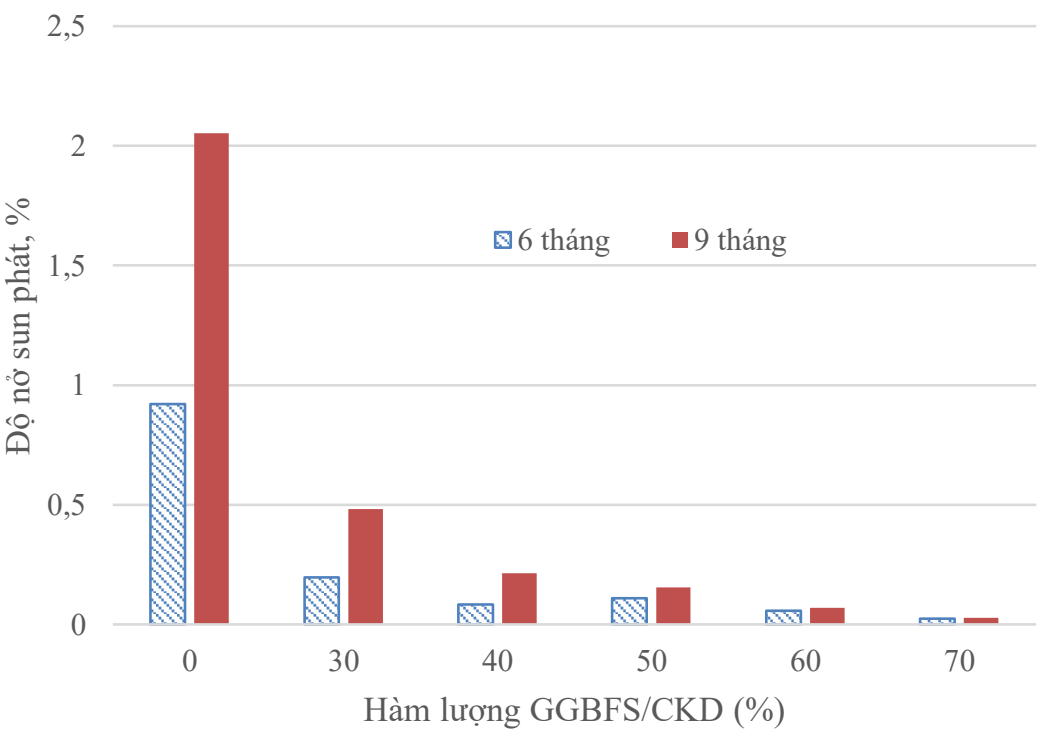

Hình 2. Độ nở sun phát sau 6 tháng và 9 tháng của bê tông sử dụng GGBFS. 


\subsection{Phản ứng kiềm - cốt liệu}

Để đánh giá khả năng hạn chế khả năng gây phản ứng kiềm cốt liệu của bê tông sử dụng GGBFS, đề tài đã tiến hành đánh giá độ nở thanh vữa sử dụng chất kết dính xi măng PC40 và bổ sung $\mathrm{Na}_{2} \mathrm{O}$ để tổng lượng kiềm tương đương là $1 \%$ (xi măng cao kiềm), hỗn hợp xi măng kiềm cao và GGBFS và cốt liệu là thủy tinh pyrex nghiền theo cấp hạt quy định theo tiêu chuẩn ASTM C441 [4]. Các thanh vữa sau đó được bảo dưỡng ở môi trường nhiệt ẩm $38 \pm 1^{\circ} \mathrm{C}$ để tăng tốc khả năng phản ứng kiềm cốt liệu. Kết quả thí nghiệm độ nở thanh vữa sử dụng xi măng cao kiềm và xi măng cao kiềm - GGBFS được thể hiện trong Bảng 6.

Từ kết quả thí nghiệm cho thây độ nở thanh vữa do phản ứng kiềm - silic giảm dần khi tăng hàm lượng sử dụng GGBFS. Điều này có thể giải thích là do trong quá trình thủy hóa rắn chắc, GGBFS sẽ phản ứng với $\mathrm{Ca}(\mathrm{OH})_{2}$ và kiềm trong xi măng tạo các sản phẩm khoáng CSH bền vững, lượng kiềm còn lại phản ứng với thủy tinh pyrex tạo khoáng gây nở thể tích không nhiều, dẫn đến độ nở do phản ứng kiềm - silic giảm đáng kể.

Hiệu quả giảm nở thể tích do phản ứng kiềm - silic thường được đánh giá thông qua độ nở thanh vữa ở tuổi 14 ngày. Do thủy tinh pyrex rất nhạy cảm với xi măng có hàm lượng kiềm cao, nên đến tuổi 14 ngày phản ứng kiềm - silic đã xẩy ra gần như hoàn toàn, điều này thể hiện rõ qua độ nở thanh vữa của xi măng poóclăng cao kiềm. Độ nở thanh vữa ở tuổi 14 ngày không lớn hơn $0,02 \%$ được coi là có khả năng hạn chế sự nở do phản ứng kiềm - silic (ASTM C989). Độ nở thanh vữa ở các tuổi dài ngày tăng hầu như không đáng kể do phản ứng kiềm - silic đã xẩy ra cơ bản trong thời gian ở tuổi sớm.

Khi sử dụng GGBFS ở tỷ lệ $40 \%$ trở lên, độ nở thanh vữa sử dụng GGBFS thấp hơn $0,02 \%$, điều này cho thấy hiệu quả của GGBFS trong việc ngăn ngừa được sự nở thể tích do phản ứng kiềm silic.

Bảng 6. Kết quả thí nghiệm độ nở do phản ứng kiềm - silic.

\begin{tabular}{|c|c|c|c|c|c|c|c|}
\hline \multirow{2}{*}{ TT } & \multirow{2}{*}{ Mẫu } & \multirow{2}{*}{ Tỷ lệ GGBFS, \% } & \multicolumn{5}{|c|}{ Độ nở thanh vữa, \% } \\
\hline & & & 14 ngày & 28 ngày & 2 tháng & 3 tháng & 6 tháng \\
\hline 1 & Xi măng cao kiềm & 0 & 0,2848 & 0,3372 & 0,3372 & 0,3396 & 0,3401 \\
\hline \multirow{5}{*}{2} & \multirow{5}{*}{ GGBFS } & 20 & 0,0408 & 0,0528 & 0,0586 & 0,0602 & 0,0612 \\
\hline & & 30 & 0,0304 & 0,0432 & 0,0468 & 0,0484 & 0,0495 \\
\hline & & 40 & 0,0196 & 0,0244 & 0,0324 & 0,0369 & 0,0383 \\
\hline & & 50 & 0,0206 & 0,0252 & 0,0319 & 0,0326 & 0,0341 \\
\hline & & 60 & 0,0182 & 0,0231 & 0,0300 & 0,0314 & 0,0321 \\
\hline
\end{tabular}

\section{Độ nở phản ứng kiềm - cốt liệu}

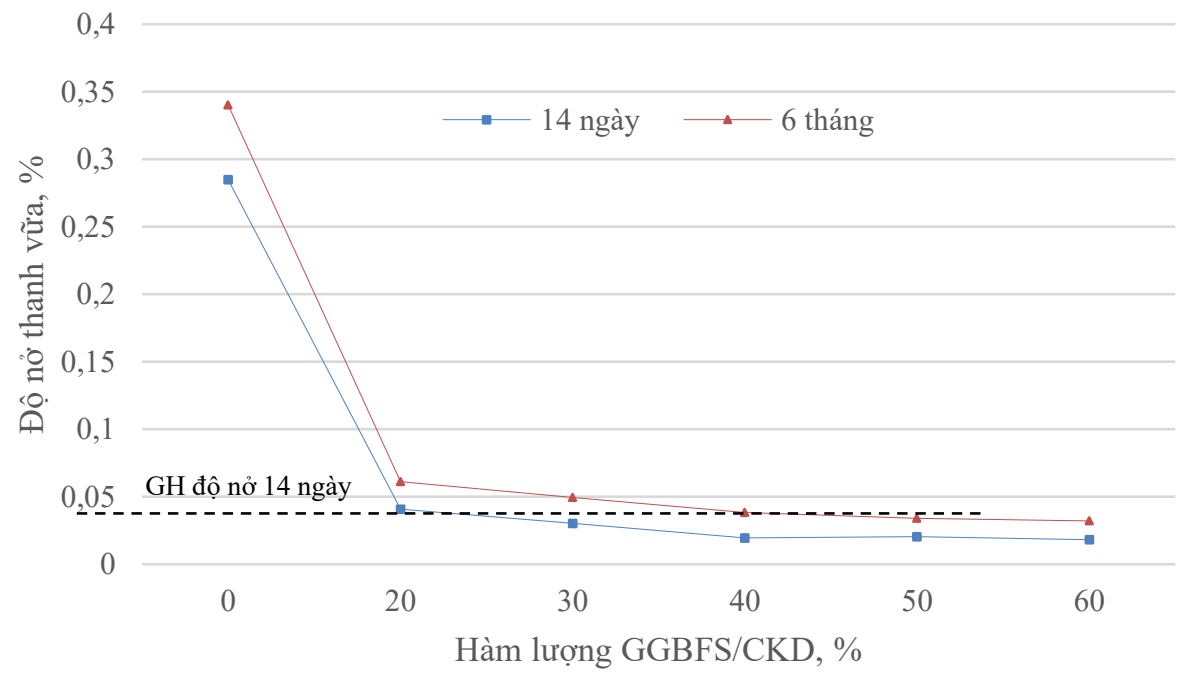

Hình 3. Ảnh hưởng hàm lượng GGBFS đến khả năng nở do phản ứng kiềm cốt liệu của bê tông theo ASTM C441. 


\section{Kết luận}

Từ kết quả nghiên cứu ảnh hưởng của xỉ hạt lò cao nghiền mịn (GGBFS) đến một số tính chất liên quan đến độ bền lâu của bê tông, có thể rút ra một số kết luận sau:

- Mức độ chống thấm ion clo và chống thấm nước của bê tông được cải thiện đáng kể khi sử dụng GGBFS so với bê tông chỉ sử dụng xi măng poóc lăng. Khi sử dụng GGBFS ở tỷ lệ 20 đến 50 \% trong chất kết dính, mức độ chống thấm của bê tông tăng tỷ lệ thuận với hàm lượng GGBFS trong chất kết dính.

- Độ nở thanh vữa do phản ứng kiềm - silic giảm dần khi tăng hàm lượng sử dụng GGBFS từ 20 đến $60 \%$, ở tỷ lệ GGBFS $40 \%$ trở lên, độ nở thanh vữa sử dụng GGBFS thấp hơn $0,02 \%$, điều này cho thấy hiệu quả của GGBFS trong việc ngăn ngừa được sự nở thể tích do phản ứng kiềm - silic.

- Sử dụng GGBFS thay thế một phần xi măng có khả năng cải thiện độ bền sun phát của thanh vữa ngâm trong môi trường sun phát $\left(\mathrm{Na}_{2} \mathrm{SO}_{4}\right)$, mức độ cải thiện phụ thuộc vào tỷ lệ GGBFS. CKD xi măng -
GGBFS với tỷ lệ thạch cao $\left(\mathrm{SO}_{3}\right)$ 2,5 \% đạt được loại xi măng hỗn hợp bền sun phát trung bình khi sử dụng GGBFS với hàm lượng 40 đến 60 \% và đạt loại xi măng hỗn hợp bền sun phát cao khi sử dụng đến 70 \% GGBFS.

\section{Tài liệu tham khảo}

[1]. Lê Trung Thành, Nguyễn Văn Tuấn, Lê Việt Hùng, Nguyễn Công Thắng, Phu gia khoáng cho xi măng và bê tông, Nhà xuất bản Xây dựng, 2019

[2]. Lương Đức Long và nnk, Báo cáo tổng kết đề tài "Nghiên cứu xi măng xì và sản xuất thử nghiệm tại Công ty xi măng Nghi Sơn", Viện Vật liệu xây dựng, 2005-2006.

[3]. American Institute of Concrete (ACI), "ACI 233R-17 Guide to the Use of Slag Cement in Concrete and Mortar," 2017.

[4]. ASTM International, "ASTM C441-11 Standard Test Method for Effectiveness of Pozzolans or Ground Blast-Furnace Slag in Preventing Excessive Expansion of Concrete Due to the Alkali-Silica Reaction". 